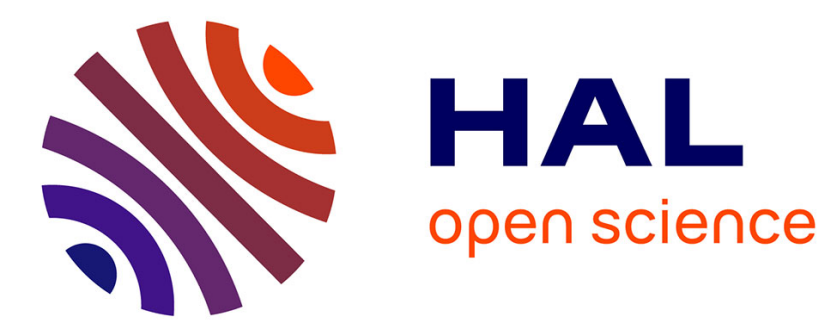

\title{
Towards Augmented Learning in Science and Engineering in Higher Education
}

Simon Carolan, Francisco Chinesta, Christine Evain, Morgan Magnin, Guillaume Moreau

\section{- To cite this version:}

Simon Carolan, Francisco Chinesta, Christine Evain, Morgan Magnin, Guillaume Moreau. Towards Augmented Learning in Science and Engineering in Higher Education. 13th IEEE International Conference on Advanced Learning Technologies, Jul 2013, Beijing, China. pp.512-513, 10.1109/ICALT.2013.169 . hal-01977283

\section{HAL Id: hal-01977283 \\ https: / hal.univ-rennes2.fr/hal-01977283}

Submitted on 14 Jan 2019

HAL is a multi-disciplinary open access archive for the deposit and dissemination of scientific research documents, whether they are published or not. The documents may come from teaching and research institutions in France or abroad, or from public or private research centers.
L'archive ouverte pluridisciplinaire HAL, est destinée au dépôt et à la diffusion de documents scientifiques de niveau recherche, publiés ou non, émanant des établissements d'enseignement et de recherche français ou étrangers, des laboratoires publics ou privés. 


\title{
Towards augmented learning in science and engineering in higher education
}

\author{
Simon Carolan ${ }^{1}$, Francisco Chinesta ${ }^{1}$, Christine Evain ${ }^{2}$, Morgan Magnin ${ }^{3}$, Guillaume Moreau ${ }^{4}$ \\ $\mathrm{GeM}^{1}, \mathrm{CRINI}^{2}, \mathrm{IRCCyN}^{3}, \mathrm{CERMA}^{4}$ \\ Ecole Centrale de Nantes \\ Nantes, France \\ [simon.carolan, francisco.chinesta, christine.evain, morgan.magnin, guillaume.moreau]@ec-nantes.fr
}

\begin{abstract}
Reference books and encyclopedic knowledge bases present learners with an important source of fundamental concepts. However, the resulting knowledge acquisition process is often hindered by the linearity that is inherent to these resources, making it difficult for learners to realize the many links that exist between these concepts. This research project aims at establishing and implementing a rich semantic model for the identification and classification of knowledge in a coreperiphery structure at the service of graduate level students of engineering sciences. This model will allow learners to obtain a global view of knowledge domains and to identify roadmaps for the knowledge acquisition process.
\end{abstract}

Keywords-enhanced learning; knowledge management; semantics;

\section{INTRODUCTION}

In recent years, higher education has been considerably transformed, widening its scope for human development and effectively democratizing the educational process. These evolutions present new challenges for our education systems as educators deal with increasingly sizable classes that contain increasingly heterogeneous student profiles [1]. The concurrent development of information and communication technologies has been instrumental in these transformations, opening access to important knowledge bases that are constantly being enhanced through collaborative development [2] [3]. Indeed, learning in such an environment of discovery is well-known to be different from learning in a more expository context. For example, in higher education contexts and particularly in engineering and applied scientific studies, it has recently been claimed that simulation-based learning enhances not only selfdetermined motivation, but also improves learning in general [4].

\section{INITIAL EXPERIMENTAL RESEARCH}

Within this context, at the Ecole Centrale de Nantes, a French graduate school of engineering, professors have been experimenting with the implementation of Information and Computer Technologies in Education initiatives built upon research and technology emanating from the institution's laboratories. These initiatives aim at bridging the gap that exists between the establishment's research activities and teaching activities. One such initiative is the development of enriched multi-scale scientific coursebooks. These coursebooks rely on the input of eZoomBook and Proper
Generalized Decomposition (PGD) technologies presented in a digitally interactive format. eZoomBook refers to a methodology and associated model for the creation, structuring and valorization of multi-scale documentation [5]. Each eZoomBook contains different versions of a same document, each version corresponding to a given level of detail and complexity. The reader is then free to navigate between these different levels in function of their available time and interest. The PGD technique provides practical means for obtaining meta-models for complex scenarios. It is a sort of vade mecum or virtual chart that contains the solution to the model for any choice of model parameters. These parametric solutions are obtained off-line by using the PGD that allows for the circumvention of the dimensionality curse that these models suffer from. These meta-models are then particularized at real-time feedback rates. PGD techniques can help in developing suitable strategies for solving complex, state-of-the-art engineering and physics problems [6]. These technologies were considered as providing a certain number of responses to the issues that have been raised by the recent changes in the educational environment. By creating coursebooks that are adaptable to the learner, it is possible to cater to the increasingly heterogeneous student profiles that teachers currently encounter. PGD software is considered as providing a practical means of bringing experiments that are physically inconceivable in the classroom environment to the students in a highly interactive and informative fashion. Through the observation of traditional university courses, we are able to establish a structural model which, combined with these technologies, existing course materials and supplementary enrichments within enhanced electronic publications, presents coherent pedagogical tools for modern learning environments [5]. The development of this structural model has led us to examine other existing knowledge bases, questioning the pertinence of their structural models in "connected" learning environments.

\section{IDENTIFICATION OF A RESEARCH PROBLEM}

Reference books, textbooks and online encyclopedic knowledge bases such as Wikipedia represent important sources of fundamental information for learners of a given subject. Through these mediums, learners are presented with a series of notions or concepts that often call upon satellite notions or concepts. They are therefore required to discover accompanying documentation, navigating from page to page 
in order to gain a complete understanding of the subject. In this situation, it is often difficult for learners to understand the explicit and implicit links between the different concepts that they encounter. Furthermore, the linear format of these resources can be considered as a hindrance to global understanding. Two objects that are far apart in a linear model can appear closer in an elevated dimension and in an infinite environment all objects are linked in one way or another. Knowledge is complex and can be considered as a multidimensional element. Recent studies have sought to define the structure of knowledge, something that is increasingly classified following a core-periphery model [7]. The semantic web is opening possibilities for the implementation of such a model in electronic resources but we are yet to see the emergence of knowledge management systems that replicate the complexity of human learning processes within them.

\section{OUR RESEARCH PROPOSAL}

By modeling and creating scalable semantic structures for the classification of scientific knowledge built upon domain ontologies [8], our aim is to provide a model for a multidimensional knowledge space. On a conceptual level, this space could be equated to an information universe. This universe will typically represent one subject area or university course, for example. Inside this universe there are planets that represent subtopics. At the core of these planets, one finds fundamental knowledge and on the periphery, one finds additional knowledge that may lead to the discovery of other planets. For the commencement of our study, we have identified two engineering domains for experimentation of this concept: composite materials and virtual reality. These domains are complex and contain cross-disciplinary aspects that make them interesting cases for study. In terms of inputs, we will be working with a series of reference books from these subject areas in electronic format. Identified sources for experimentation include The Intimate Life of Composite Materials [9] and Traité de la réalité virtuelle [10]. These documents have been selected as they gather entire scientific communities in their authorship, have undergone a rigorous publishing process and are recognized publications in their respective domains. We will be examining both the textual and the visual contents of these works using artificial neural networks and hybrid classification processes combining probabilistic and linguistic approaches in order to establish a coherent coreperiphery model for the classification of the contents [11]. The results of this process will be verified through the elicitation of key concepts by domain experts. The resulting models will be used to create domain ontologies using Protégé OWL and optimized to reflect the course requirements of postgraduate engineering students. Once the model is established, external knowledge sources including the aforementioned online encyclopedic knowledge bases can be integrated, to complete the knowledge environment and establish uncharted links. This information will be mapped into an evolving multidimensional environment where we will integrate sequential models into the data set in order to provide learners with suggested paths or routes for discovery of the domain, subject to their learning profile. We imagine these semantic "books" or knowledge environments to accompany learners through their university education and beyond, offering seemingly endless possibilities for transforming themselves into lifelong learners [12]. The established model will also prove to be an interesting tool for knowledge management and professional development in industry, where companies hold a great deal of unclassified internal and external data that could be of benefit if channeled correctly. In addition, we believe that this may provide the grounding for the development of other novel document annotation tools. Indeed, the growing intelligence of documents through semantic tools means that one day soon, a document will know its contents well enough to be able to answer learner interrogations directly.

\section{BIBLIOGRAPHY}

[1] Romainville, M., (2004). Esquisse d'une didactique universitaire. Revue francophone de gestion: Deuxième prix de l'innovation pédagogique en sciences de gestion pp. 5-24. Paris: CIDEGEF.

[2] Blumenfeld, P. C., Soloway, E., Marx, R. W., Krajcik, J. S., Guzdial, M. \& Palincsar, A. Motivating Project-Based Learning: Sustaining the Doing, Supporting the Learning. Educational Psychologist, vol. 26, n. 3-4, Routledge. New York: 1991.

[3] Goodman, P. S., (Ed.). Technology Enhanced Learning: Opportunities for Change, Taylor \& Francis. New York: 2001.

[4] Rutten, N., van Joolingen, W. R., van der Veen, J. T., (2012). The learning effects of computer simulations in science education. Computers \& Education, vol. 58, n. 1, January 2012, pp. 136-153.

[5] Carolan, S., Chinesta, P., Evain, C., Moreau, G. et Magnin, M., (2012). Developing Models for Enhanced Learning in Engineering. Proceedings of the 6th Centrale Beihang Workshop, Lille: France. http://hal.archives-ouvertes.fr/hal-00783543.

[6] Chinesta, F., Leygue, A. Bordeu, F., Aguado, J. V., Cueto, E., Gonzalez, D., Alfaro, I., Ammar, A. et Huerta, A., (2013). Parametric PGD based computational vademecum for efficient design, optimization and control. Archives of Computational Methods in Engineering, vol. 20, n. 1, pp. 31-59.

[7] Zhang, Y., (2011). Learning, Innovating, and an Emerging Core of Knowledge, Conference on Information Systems and Technology (CIST), Charlotte, November, 2011.

[8] Hsieh, S-H., Lin, H-T., Chi, N-W., Chou, K-W., Lin, K-Y, (2011). Enabling the development of base domain ontology through extraction of knowledge from engineering domain handbooks. Advanced Engineering Informatics, vol. 25, n. 2, April 2011, Pages 288-296.

[9] Chinesta, F. \& Evain, C. The Intimate Life of Composite Materials. Editions Publibook, Paris: 2009.

[10] Fuchs, P. \& Moreau, G., (Eds.) Traité de la réalité virtuelle. Presses de l'Ecole des Mines, Paris: 2006-9.

[11] Campedel, M. \& Hoogstoël, P., (Eds.). Sémantique et multimodalité en analyse de l'information. Lavoisier - Hermes Science, Paris: 2011.

[12] Laurillard, D., Oliver, M., Wasson, B. \& Hoppe, U., (2009) Implementing Technology-Enhanced Learning. TechnologyEnhanced Learning, 2009, Part 5, pp. 289-306, Springer. 